\title{
The impact of preoperative etiology on emergent pancreaticoduodenectomy for non-traumatic patients
}

\author{
Chun-Yi Tsai ${ }^{1,2}$, Bo-Ru Lai ${ }^{1,2}$, Shang-Yu Wang ${ }^{2,3}$, Chien-Hung Liao ${ }^{2,3}$, Yu-Yin Liü ${ }^{1,2}$, Shih-Ching Kang ${ }^{2,3}$, \\ Chun-Nan Yeh ${ }^{1,2^{*}}$, Yi-Yin Jan ${ }^{1,2}$ and Ta-Sen Yeh ${ }^{1,2}$
}

\begin{abstract}
Background: Emergent pancreaticoduodenectomy is a life-saving procedure in certain clinical scenarios when all the conservative treatment fails. The indications can be limited into perforation and bleeding. To clarify the impact of etiology on surgical outcomes of emergent pancreaticoduodenectomy for non-trauma, we analyzed our patients and performed a literature review.

Methods: We reviewed 931 consecutive pancreaticoduodenectomies performed at our institute between January 2001 and July 2015. Patients with emergent pancreaticoduodenectomy for non-trauma etiologies were enrolled, whereas those who suffered from caustic injuries were excluded. The keywords "emergent/emergency" and "pancreaticoduodenectomy/pancreatoduodenectomy" were applied in a literature search. The universally available data for all the enrolled patients including etiology, surgical complications, outcomes, and hospital stays were analyzed. Univariate and multivariate logistic analysis for the contributing factors to surgical mortality were performed.

Results: Six out of 931 (0.6\%) registered pancreaticoduodenectomies matched our criteria of inclusion. The literature review obtained 4 series and 7 case reports, which when combined with our patients yielded a cohort of 31 emergent pancreaticoduodenectomies with 13 cases of perforation and 18 of bleeding. The rate of emergent pancreaticoduodenectomy for non-traumatic etiologies is similar between the present study and the other 3 series, ranging from 0.3 to $3 \%$. The overall surgical complication rate was $\mathbf{8 3 . 9 \%}$. The rate of surgical mortality is significantly higher than in elective pancreaticoduodenectomy by propensity score matching with age and gender (19.4 versus 3.2\%, $P=0.015$ ). Univariate and multivariate logistic regression disclosed that etiology is the only preoperative risk factor for surgical mortality (perforation versus bleeding; odds ratio $=39.494, P=0.031$ ).

Conclusions: Emergent pancreaticoduodenectomy remains a rare operation. Surgical morbidity and mortality are higher than with elective pancreaticoduodenectomy among different reported series. By sorting the preoperative etiologies into two groups, perforation carries a higher risk of surgical mortality than bleeding.
\end{abstract}

Keywords: Pancreaticoduodenectomy, Emergent pancreaticoduodenectomy, Gastrointestinal bleeding, Gastrointestinal perforation, Surgical complication, Lethality

\footnotetext{
* Correspondence: yehchunnan@gmail.com

${ }^{1}$ Department of General Surgery, Chang Gung Memorial Hospital, Chang

Gung University, Linkou branch, No.5, Fu-Xing Street, Kueishan District,

Taoyuan City 333, Taiwan

${ }^{2}$ Chang Gung University, No. 259, Wen Hua First Road, Kueishan District,

Taoyuan City 333, Taiwan

Full list of author information is available at the end of the article
} 


\section{Background}

Pancreaticoduodenectomy (PD) is a procedure for managing lesions of various etiologies involving the region of duodenum, distal bile duct, and pancreatic head $[1,2]$. Due to the refinement of preoperative management and surgical techniques, surgical morbidity and mortality rates of $\mathrm{PD}$ have decreased in high-volume institutes in recent decades $[3,4]$. However, it is still a technically demanding and complex procedure. Regardless of the prognosis of underlying malignancies, which are the majority of indications for patients undergoing $\mathrm{PD}$, the complications of PD have been meticulously studied [5]. Emergent PD (EPD) were encountered by surgeons in traumatic scenarios [6-9]. EPD for non-traumatic etiologies, such as perforation-related peritonitis or uncontrolled bleeding around the pancreaticoduodenal area, has been sporadically reported. In order to minimize the complications caused by pancreaticojejunostomy, some authors proposed a "staged reconstruction" and obtained satisfying results [10]. Sakakima et al [11] reported a successful EPD with a similar concept of staged reconstruction of pancreaticojejunostomy. In contrast to reports focusing on operative management, there have been no reports regarding preoperative predictors for surgical outcomes of EPDs. As one of the referring centers in Taiwan, we reviewed our patients and cases from the literature that underwent EPD for non-traumatic etiologies to clarify the impact of etiology on the outcomes of EPD.

\section{Methods}

Between January 2000 and July 2015, 931 consecutive PDs (classic Whipple's operation and pylorus-preserving PD) were performed at the Department of Surgery, Chang Gung Memorial Hospital, Linkou, Taiwan. The indications for emergent PD of non-traumatic etiologies include (1) incomplete preoperative preparation and management for neoplastic lesions (2) operation for failed non-surgical hemostasis (3) emergent operations for peritonitis/intraabdominal infection/ or iatrogenic perforations. Patients necessitating EPDs due to caustic injuries were excluded because of multivisceral resection and the systemically catastrophic cascade resulting from digestive chemicals [12]. Patients who met the inclusion criteria were analyzed regarding gender, age, etiology, body mass index (BMI), underlying diseases, preoperative severity (APACHE II score), the interval to the reconstruction, the length of hospital stay, surgical complications, and mortality. Surgical complications were described and classified according to the Clavien-Dindo classification [13]. Surgical mortality is defined as death either within 30 days or during the same admission after EPD. For patients without surgical mortality, we reviewed their performance and sequelae during follow-up.

The literature review was performed via MEDLINE and PubMed focusing on English language literatures with the keywords, "emergent/emergency" and "pancreaticoduodenectomy/pancreatoduodenectomy". We then selected only literatures with full text published between the year 2001 and 2015. From the series obtained by this combination, including case reports, the patients designated as non-traumatic etiologies were extracted and included in our study. Statistical analyses were done with IBM SPSS. Values of $P<0.05$ were considered statistically significant. All results were expressed as mean $+/-$ standard deviations. Univariate and multivariate logistic regression analyses were applied to determine the factors affecting surgical mortality.

\section{Results}

From a total of 931 patients with PD, only 6 underwent EPD from 2001 to 2015 (Table 1 and Fig. 1). There were

Table 1 Demographic data of patients who underwent emergent pancreaticoduodenectomy for non-traumatic etiologies in our series

\begin{tabular}{|c|c|c|c|c|c|c|}
\hline Sex/age/indication & Cancer & $\begin{array}{l}\text { Procedure/blood } \\
\text { loss (ml) }\end{array}$ & $\begin{array}{l}\text { APACHE II score/BMl/Hb } \\
\text { (g/dL)/albumin (g/dL) }\end{array}$ & Complication/grading & Death & $\begin{array}{l}\text { Hospital } \\
\text { stay (days) }\end{array}$ \\
\hline $\begin{array}{l}\text { M/70/internal bleeding after } \\
\text { partial pancreatectomy }\end{array}$ & No & $C W / 1000$ & $17 / 18.6 / 13.6 / 4.9$ & Bile leakage/2 & No & 109 \\
\hline $\begin{array}{l}\text { M/49/bleeding duodenal } \\
\text { lymphoma }\end{array}$ & Lymphoma & $\mathrm{CW} / 20$ & $16 / 20.1 / 11 / 2.2$ & $\begin{array}{l}\text { P-duct leakage with } \\
\text { Peritonitis/3 }\end{array}$ & No & 54 \\
\hline $\begin{array}{l}\text { F/78/A-loop perforation after } \\
\text { ERCP }\end{array}$ & GC & $\mathrm{CW} / 400$ & $12 / 21.3 / 9.4 / 3.3$ & $\mathrm{MOF} / 4$ & $Y_{e s}^{a}$ & 16 \\
\hline $\begin{array}{l}\text { F/58/A-loop obstruction and } \\
\text { perforation }\end{array}$ & No & CW/500 & 6/17.3/11.9/3.2 & $\begin{array}{l}\text { Retro-peritoneal } \\
\text { infection } / 3\end{array}$ & No & 17 \\
\hline M/32/bowel ischemia & No & CW/2850 & 19/24.3/11.3/1.9 & $\begin{array}{l}\text { Septic shock with liver } \\
\text { and renal failure } / 5\end{array}$ & Yes & 11 \\
\hline F/39/duodenal ulcer bleeding & No & $C W / 1000$ & $17 / 19.5 / 4.5 / 2.2$ & Wound infection/2 & No & 40 \\
\hline 53.5 & & 750 & 16.5/19.8/11.2/2.7 & & & 28.5 \\
\hline
\end{tabular}

ERCP endoscopic retrograde cholangiopancreaticography, GC gastric cancer, $C W$ classic Whipple's operation, $B M I$ body mass index, $M O F$ multi-organ failure ${ }^{a}$ The patient had been discharged and died of complications of MOF 8 months after initial EPD 


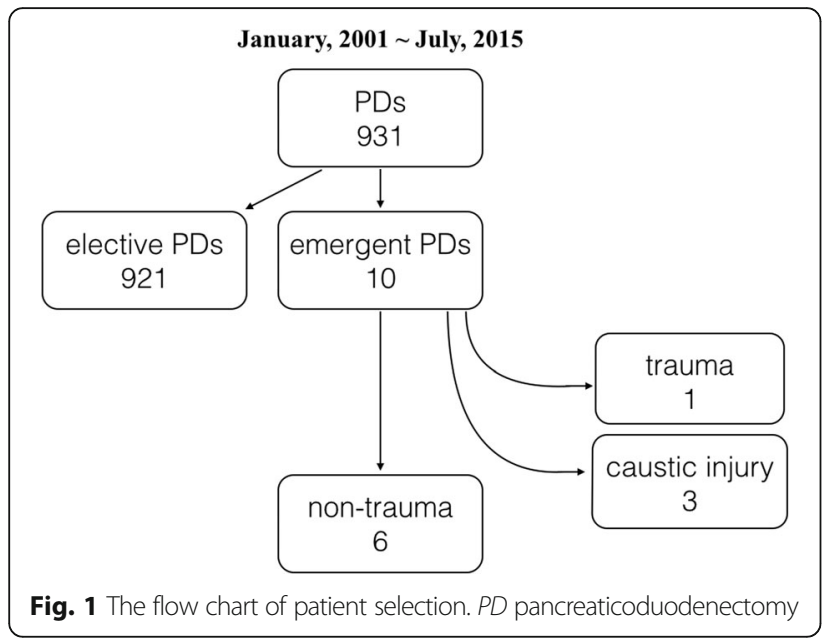

3 male and 3 female patients with mean age 53.5 years old (range: 32 to 78). The clinical scenarios of these patients were described as following: the first patient underwent partial pancreactomy near pancreatic head and complicated with hemorrhagic shock. He underwent EPD after failure of bleeding control by angiographic embolization. The second patient presented to emergency department with a massively bleeding duodenal tumor and failed to angiographic embolization. $\mathrm{He}$ underwent EPD to treat the life-threatening bleeding and finally diagnosed with lymphoma. The third patient had underlying gastric cancer status post subtotal gastrectomy with Billroth II gastrojejunostomy. She received endoscopic retrograde cholangiopancreatography (ERCP) for choledocholithotomy and complicated with afferent loop perforation. Owing to delayed diagnosis of perforation, the patient developed sepsis, and the regional bowel tissue disclosed insufficiency. EPD was performed by the surgeon's decision. The fourth patient suffered from extensive afferent loop ischemia due to obstruction and strangulation. The fifth patient presented with generalized peritonitis owing to duodenal ischemia and necrosis with unknown cause. The sixth patient presented with hemorrhagic shock because of a huge duodenal ulcer at the mesenteric site, failed to endoscopic hemostasis and angiographic embolization. All of the patients had surgical complications of varying severity, including one case of in-hospital mortality. One patient was discharged after EPD with multi-organ failure (grade 4 surgical complication); however, she had repeated admission afterwards and died 8 months after the operation. The patient was also designated as surgeryrelated mortality. The APACHE II score ranged from 6 to 19 among these patients, while the patient who suffered from in hospital mortality carried the highest score. Two of the patients had underlying malignancy (33\%). All the parameters, including age, BMI, albumin
Table 2 Results of cases from literature review and our series

\begin{tabular}{llllllll}
\hline $\begin{array}{l}\text { Study } \\
\text { year }\end{array}$ & Author & PD & EPD & $\begin{array}{l}\text { EPD for } \\
\text { non-trauma }\end{array}$ & $\begin{array}{l}\text { Mortality } \\
\text { rate }\end{array}$ \\
\hline 2001 & Tuech & N/A & & 1 & N/A & $0 \%$ \\
2002 & Z'graggen & 417 & 4 & $1.0 \%$ & 4 & $1.0 \%$ & $25 \%$ \\
2004 & Sakakima & N/A & & 1 & N/A & $0 \%$ \\
2006 & Maeda & N/A & & 1 & N/A & $0 \%$ \\
2007 & Stratigos & N/A & & 1 & N/A & $0 \%$ \\
2010 & Standop & 301 & 6 & $2.0 \%$ & 6 & $2.0 \%$ & $16.7 \%$ \\
2010 & Hecker & N/A & & 1 & N/A & $0 \%$ \\
2010 & Michael & N/A & & 1 & N/A & $0 \%$ \\
2013 & Lupaşcu & N/A & & 1 & N/A & $0 \%$ \\
2014 & Gulla & 1166 & 10 & $0.9 \%$ & 3 & $0.3 \%$ & $0 \%$ \\
2015 & Lissidini & 169 5 & $3.0 \%$ & 5 & $3.0 \%$ & $40 \%$ \\
& Present study & 931 & 10 & $1.1 \%$ & 6 & $0.6 \%$ & $33.3 \%$ \\
& Overall & 2984 & & 31 & & $19.4 \%$ \\
\hline
\end{tabular}

$P D$ pancreaticoduodenectomy, EPD emergent pancreaticoduodenectomy

level, and intraoperative blood loss, had a wide range of values.

Table 2 presented 31 EPD accounting for $1.84 \%$ of all 2984 cases who underwent EPD for non-traumatic etiologies from the literature and the present series $[8,11,14-22]$. The rate of EPD for non-traumatic etiologies is similar between the present study and the other 3 series, ranging from 0.3 to $3 \%$.

Table 3 shows the propensity score of age and gender in the cohort receiving elective PD for our database shows ratio of 1:2. EPDs disclosed mortality rate of 19.4 versus $3.2 \%(P=0.015)$ in non-EPD.

Table 4 shows the association factors contributing to surgical mortality of EPD, including age, gender, etiology, malignancy, and length of hospital stay. However, only

Table 3 The 1:2 propensity score matching comparison (age and gender) between EPD and elective PD relating to surgical mortality

\begin{tabular}{lll} 
EPD & Elective PD & $P$ value \\
31 & 62 & \\
\hline
\end{tabular}

\begin{tabular}{llll}
\hline Gender & & 37 & \\
Male & 19 & 25 & \\
Female & 12 & & \\
Age & & $57.2(14.5)$ & $P=0.889$ \\
Mean ( \pm S.D.) & $56.7(14.5)$ & 58.0 & \\
Median & 58.0 & $29-86$ & \\
Range & $32-85$ & & \\
Surgical mortality & & 2 & \\
Yes & 6 & 60 & \\
No & 25 & 3.2 & \\
$\%$ & 19.4 & & \\
\hline
\end{tabular}

EPD emergent pancreatoduodenectomy, $P D$ pancreatoduodenectomy 
Table 4 Univariate and multivariate logistic regression analysis of risk factors related to surgical mortality of the new cohort comprising 31 patients

\begin{tabular}{|c|c|c|c|c|c|c|c|}
\hline \multirow[t]{2}{*}{ Variables } & & \multicolumn{3}{|c|}{ Univariate analysis } & \multicolumn{3}{|c|}{ Multivariate analysis } \\
\hline & & $\mathrm{OR}$ & $95 \% \mathrm{Cl}$ & $P$ value & $\mathrm{OR}$ & $95 \% \mathrm{Cl}$ & $P$ value \\
\hline$\overline{\text { Age }}$ & Year & 1.028 & $0.964-1.097$ & 0.401 & 1.013 & $0.907-1.132$ & 0.817 \\
\hline Gender & Male vs. female & 3.929 & 0.399-38.704 & 0.241 & 19.174 & $0.468-785.328$ & 0.119 \\
\hline Etiology & Perforation vs. bleeding & 10.625 & $1.059-106.573$ & 0.045 & 39.494 & $1.395-1117.856$ & 0.031 \\
\hline Cancer & Cancer vs. no cancer & 2.545 & $0.391-16.550$ & 0.328 & 5.375 & $0.183-157.541$ & 0.329 \\
\hline Hospital stay & Day & 0.990 & $0.962-1.019$ & 0.501 & 0.979 & $0.936-1.023$ & 0.338 \\
\hline
\end{tabular}

patients suffering from perforation who received EPDs are the independent factor associating with surgical mortality rate of EPD, demonstrated by the multivariate logistic regression analysis. (perforation versus bleeding; odds ratio $=39.494, P=0.031$ )

\section{Discussion}

First, it should be emphasized that although the morbidity and mortality rate of PD had decreased since the first description of PD in 1935 [2], surgical outcome was still dismal in experienced institutes for decades. The meticulous preoperative preparation for the most complex abdominal operations has improved its outcomes. In this report, we demonstrated that EPD for non-trauma is an uncommonly performed procedure with incidence ranging from 0.3 to $3 \%$ among elective PDs.

Secondly, as shown in our report, the overall complication rate and surgical mortality rate for EPD are 83.9 and $19.4 \%$, respectively. The propensity score match further disclosed the significantly higher surgical mortality of EPDs when compared with elective PDs (19.4 versus $3.2 \%)$. The possible explanation for the higher morbidity and mortality of EPD is that emergent surgeries possess potential unpreparedness with respect to elective surgeries [23].

Thirdly, and most importantly, is that the report clarified the preoperative predictors for poor outcome of EPD. As we know, the indications for emergent visceral operations can be narrowed to two aspects: perforation and bleeding. Visceral perforation induces secondary peritonitis and results in sepsis [24], which compromises the patient's preoperative condition more than mere bleeding. Previous reports focused on the impact of etiology (perforation or bleeding) on surgical outcomes of emergent gastrointestinal surgery. For emergent gastrectomy, the etiology had no association with surgical mortality $[25,26]$. Similar to previous reports regarding complicated colonic diverticular disease, perforation is one of the predictors for surgical mortality in EPD [27]. In this study, we gathered available preoperative parameters along with etiology for EPD to clarify the factors that affect surgical outcomes. As demonstrated in the univariate and the multivariate logistic regression analysis, patients suffering from perforation undergoing EPDs had significantly higher association with surgical mortality than those suffering from bleeding. However, the result may reflect the biased selection of this cohort because there were more case reports of successful EPDs in managing patient with intractable bleeding, and only one of the seven case reports is related to perforation.

\section{Conclusions}

This study disclosed that the rates of EPD for nontraumatic etiologies are low, ranging from 0.3 to $3 \%$ among elective PDs. EPDs have relatively higher surgical mortalities compared to well-prepared, elective PDs. Among EPDs, patients suffering from perforation might have a higher risk of surgical mortality than those suffering from bleeding when the operation is warranted.

\section{Abbreviations}

EPD: Emergent pancreaticoduodenectomy; PD: Pancreaticoduodenectomy

\section{Acknowledgements \\ We appreciate all the medical staff those meticulously took care of such complicated patients.}

\section{Funding}

There is no funding provided for the research or publication of the manuscript.

\section{Availability of data and materials}

The dataset supporting the conclusions of this article is included within the tables.

\section{Authors' contributions}

$C T$ and $C Y$ were the major contributors in drafting the manuscript. $B L$ and SW contribute to the study concept and design. CL, YL, SK, and YJ contributed to acquisition of data. $C T, B L$, and SW performed the analysis and interpretation of data. TY and CY provided the critical revision of the manuscript. All authors read and approved the final manuscript.

\section{Competing interests}

The authors declare that they have no competing interests.

\section{Consent for publication}

Verbal consent was provided by each of the six participants enrolled in our study.

Ethics approval and consent to participate

This manuscript was related to the approved study by the Chang Gung Memorial Hospital, Linkou branch, Taiwan, Institutional Review Board, number 104-4010C. 


\section{Publisher's Note}

Springer Nature remains neutral with regard to jurisdictional claims in published maps and institutional affiliations.

\section{Author details}

${ }^{1}$ Department of General Surgery, Chang Gung Memorial Hospital, Chang Gung University, Linkou branch, No.5, Fu-Xing Street, Kueishan District, Taoyuan City 333, Taiwan. ${ }^{2}$ Chang Gung University, No. 259, Wen Hua First Road, Kueishan District, Taoyuan City 333, Taiwan. ${ }^{3}$ Department of Traumatology and Emergent Surgery, Chang Gung Memorial Hospital, Chang Gung University, Linkou branch, No.5, Fu-Xing Street, Kueishan District, Taoyuan City 333, Taiwan.

Received: 5 March 2017 Accepted: 25 April 2017

Published online: 02 May 2017

\section{References}

1. Pancreatric Section BSoG, Pancreatic Society of Great B, Ireland, Association of Upper Gastrointestinal Surgeons of Great B, Ireland, Royal College of P, Special Interest Group for Gastro-Intestinal R. Guidelines for the management of patients with pancreatic cancer periampullary and ampullary carcinomas. Gut. 2005:54 Suppl 5:v1-16.

2. Whipple $A O$, Parsons WB, Mullins CR. Treatment of carcinoma of the ampulla of vater. Ann Surg. 1935;102(4):763-79.

3. Winter JM, Cameron JL, Campbell KA, Arnold MA, Chang DC, Coleman J, Hodgin MB, Sauter PK, Hruban RH, Riall TS, et al. 1423 pancreaticoduodenectomies for pancreatic cancer: a single-institution experience. J Gastrointest Surg. 2006;10(9): 1199-210. discussion 1210-1191.

4. Balzano G, Zerbi A, Capretti G, Rocchetti S, Capitanio V, Di Carlo V. Effect of hospital volume on outcome of pancreaticoduodenectomy in Italy. Br J Surg. 2008:95(3):357-62.

5. Joliat GR, Petermann D, Demartines N, Schafer M. Prediction of complications after pancreaticoduodenectomy: validation of a postoperative complication score. Pancreas. 2015;44(8):1323-8.

6. Chinnery GE, Krige JE, Kotze UK, Navsaria P, Nicol A. Surgical management and outcome of civilian gunshot injuries to the pancreas. Br J Surg. 2012;99 Suppl 1:140-8.

7. Asensio JA, Petrone P, Roldan G, Kuncir E, Demetriades D. Pancreaticoduodenectomy: a rare procedure for the management of complex pancreaticoduodenal injuries. J Am Coll Surg. 2003;197(6):937-42.

8. Gulla A, Tan WP, Pucci MJ, Dambrauskas Z, Rosato EL, Kaulback KR, Pundzius J, Barauskas G, Yeo CJ, Lavu H. Emergent pancreaticoduodenectomy: a dual institution experience and review of the literature. J Surg Res. 2014;186(1):1-6.

9. Lin BC, Chen RJ, Fang JF, Hsu YP, Kao YC, Kao JL. Management of blunt major pancreatic injury. J Trauma. 2004;56(4):774-8.

10. Miyagawa S, Makuuchi M, Kawasaki S, Ogiwara M. Second-stage pancreatojejunostomy following pancreatoduodenectomy in high-risk patients. Am J Surg. 1994;168(1):66-8.

11. Sakakima Y, Inoue S, Fujii T, Hatsuno T, Takeda S, Kaneko T, Nagasaka T, Nakao A. Emergency pylorus-preserving pancreatoduodenectomy followed by second-stage pancreatojejunostomy for a gastrointestinal stromal tumor of the duodenum with an intratumoral gas figure: report of a case. Surg Today. 2004;34(8):701-5.

12. Contini S, Scarpignato C. Caustic injury of the upper gastrointestinal tract: a comprehensive review. World J Gastroenterol. 2013;19(25):3918-30.

13. Clavien PA, Barkun J, de Oliveira ML, Vauthey JN, Dindo D, Schulick RD, de Santibanes E, Pekolj J, Slankamenac K, Bassi C, et al. The Clavien-Dindo classification of surgical complications: five-year experience. Ann Surg. 2009; 250(2):187-96.

14. Tuech JJ, Pessaux P, Regenet N, Bergamaschi R, Arnaud JP. Emergency pancreaticoduodenectomy with delayed reconstruction for bleeding: a life saving procedure. Int J Pancreatol. 2001;29(1):59-62.

15. Z'Graggen K, Strobel O, Schmied BM, Zimmermann A, Buchler MW. Emergency pancreatoduodenectomy in nontrauma patients. Pancreas. 2002;24(3):258-63.

16. Maeda H, Okabayashi T, Kobayashi M, Araki K, Kohsaki T, Nishimori I, Onish S, Ito S, Ogawa Y, Okuda H, et al. Emergency pancreatoduodenectomy for pancreatic metastasis from renal cell carcinoma in a patient with von Hippel-Lindau disease: a case report. Dig Dis Sci. 2006;51(8):1383-7.

17. Stratigos P, Kouskos E, Kouroglou M, Chrisafis I, Fois L, Mavrogiorgis A, Axiotis E, Zamtrakis S. Emergency pancreatoduodenectomy (whipple procedure) for massive upper gastrointestinal bleeding caused by a diffuse B-cell lymphoma of the duodenum: report of a case. Surg Today. 2007:37(8):680-4.

18. Standop J, Glowka T, Schmitz V, Schaefer N, Hirner A, Kalff JC. Emergency Kausch-Whipple procedure: indications and experiences. Pancreas. 2010; 39(2):156-9.

19. Hecker A, Hecker B, Bassaly B, Hirschburger M, Schwandner T, Janssen H, Padberg W. Dramatic regression and bleeding of a duodenal GIST during preoperative imatinib therapy: case report and review. World J Surg Oncol. 2010:8:47.

20. Ujiki MB, Adler A, Swanstrom LL, Diwan TS, Hansen PD. Emergent pancreaticoduodenectomy for Dieulafoy lesion of the duodenum. Am Surg. 2010;76(6):656-7.

21. Lupascu C, Ursulescu C, Andronic D. Emergency pancreaticoduodenectomy for bleeding pancreatic pseudoaneurysm in patient with common mesentery and replaced right hepatic artery. Chirurgia (Bucur). 2013;108(6):910-4.

22. Lissidini G, Prete FP, Piccinni G, Gurrado A, Giungato S, Prete F, Testini M. Emergency pancreaticoduodenectomy: when is it needed? A dual non-trauma centre experience and literature review. Int J Surg. 2015;21 Suppl 1:S83-88.

23. Ingraham AM, Cohen ME, Raval MV, Ko CY, Nathens AB. Comparison of hospital performance in emergency versus elective general surgery operations at 198 hospitals. J Am Coll Surg. 2011;212(1):20-8. e21.

24. Merrell RC. The abdomen as source of sepsis in critically ill patients. Crit Care Clin. 1995; 11(2):255-72.

25. So JB, Yam A, Cheah WK, Kum CK, Goh PM. Risk factors related to operative mortality and morbidity in patients undergoing emergency gastrectomy. $\mathrm{Br}$ Surg. 2000:87(12):1702-7.

26. Kasakura Y, Ajani JA, Mochizuki F, Morishita Y, Fujii M, Takayama T. Outcomes after emergency surgery for gastric perforation or severe bleeding in patients with gastric cancer. J Surg Oncol. 2002;80(4):181-5.

27. Hussain A, Mahmood H, Subhas G, El-Hasani S. Complicated diverticular disease of the colon, do we need to change the classical approach, a retrospective study of 110 patients in southeast England. World J Emerg Surg. 2008:3:5.

\section{Submit your next manuscript to BioMed Central and we will help you at every step:}

- We accept pre-submission inquiries

- Our selector tool helps you to find the most relevant journal

- We provide round the clock customer support

- Convenient online submission

- Thorough peer review

- Inclusion in PubMed and all major indexing services

- Maximum visibility for your research

Submit your manuscript at www.biomedcentral.com/submit
Biomed Central 